\title{
Note on the medical grading of enlisted men
}

From January 1916 until November 1917, men who passed their army medical examinations were placed into one of three categories: A, B and C (the latter two with sub-divisions). An 'A' man was fit for general service: that is, to serve in the front line. Men certified as $\mathrm{B} 1$ or $\mathrm{C} 1$ were regarded as fit for support duties, respectively abroad or at home only; $\mathrm{B}_{2}$ and $\mathrm{C}_{2}$ men were allocated to garrison duties on the same basis; those classed as $B_{3}$ and $C_{3}$ similarly to clerking or other sedentary work. From November 1917 , following the radical reorganization of the examination system and the replacement of military by civilian medical boards, newly enlisted men were allocated levels of fitness as follows: Grade I (old Category A), II (B1, $\mathrm{C}_{1}$ ), III (B2 and 3, $\mathrm{C}_{2}$ and 3 ), IV (failed). 
James McDermott - 9781847794185 Downloaded from manchesterhive.com at $04 / 26 / 2023$ 03:47:59AM via free access 